\title{
PENGARUH WAKTU PERENDAMAN DALAM AIR, KADAR PATI DAN KADAR LIGNIN TERHADAP SIFAT FISIK DAN MEKANIK BAMBU AMPEL (Bambusa vulgaris Schard)
}

\author{
Abdurachman, Agus Ismanto* \\ Pusat Penelitian dan Pengembangan Hasil Hutan \\ Jl. Gunungbatu No. 5. Bogor 16610 \\ *e-mail: aismanto59@gmail.com
}

\begin{abstract}
The effect of immersion time in the water, starch and lignin content physical and mechanical properties of Ampel bamboo (Bambusa vulgaris Schard)
\end{abstract}

\begin{abstract}
The studied effect of immersion time in the water on physical and mechanical properties of ampel bamboo had been studied at the Forest Products Research and Development Center Bogor. Round Bamboo of ampel species (Bambusa vulgaris Schard) a length of $50 \mathrm{~cm}$ was immersed in running water, stagnant and in the sludge for 7, 14, 21 and 28 days. Then the changes in starch and lignin content, physical and mechanical properties were evaluated. The physical properties studied were evaluated density and moisture content, while mechanical properties were bending and parallel tensile strength of fiber. The results showed that the media and immersion time significantly affect the density and moisture content, but did not affect the physical and mechanical properties. Increased starch content in a variety of treatments, especially on immersion in water, otherwise the lignin content decreases, causing a decrease in the nature of Modulus of Elasticity (MOE) and Modulus of Rupture (MOR). Immersion in stagnant water better than by soaking in the mud and in running water.
\end{abstract}

Keywords: Bambusa vulgaris Schard, media, immersion time, physical and mechanical properties

\begin{abstract}
ABSTRAK
Penelitian pengaruh waktu perendaman dalam air terhadap sifat fisik dan mekanik bambu ampel (bambusa vulgaris) telah dilakukan di Pusat Penelitian dan Pengembangan Hasil Hutan Bogor. Bambu bulat berukuran panjang $50 \mathrm{~cm}$ direndam dalam air mengalir, tergenang dan lumpur selama 7, 14, 21 dan 28 hari, kemudian diamati perubahan kadar pati,diuji sifat fisik dan mekaniknya. Sifat fisik yang diteliti adalah kerapatan dan kadar air, sedangkan sifat mekanik adalah keteguhan lentur dan tarik sejajar serat. Hasil penelitian menunjukkan bahwa media dan waktu rendaman berpengaruh nyata terhadap kerapatan dan kadar air, tetapi tidak berpengaruh terhadap sifat fisis dan mekanis bambu yang diteliti. Kadar pati meningkat pada berbagai perlakuan terutama pada rendaman dalam air mengalir, sebaliknya kandungan lignin menurun sehingga menyebabkan penurunan sifat Modulus elastisitas (MOE) dan keteguhan lentur maksimum (MOR). Perendaman dalam air tergenang lebih baik dibandingkan dengan cara perendaman dalam lumpur maupun dalam air mengalir.
\end{abstract}

Kata kunci : Bambusa vulgaris Schard, media, waktu perendaman, sifat fisis dan mekanis

\section{PENDAHULUAN}

Bambu merupakan hasil hutan non kayu yang tergolong murah harganya, besar jumlahnya, dan digunakan secara luas untuk berbagai keperluan. Tanaman ini menyebar di seluruh kawasan nusantara (Kuswanto, 2000). Potensi jenis bambu di dunia tercatat lebih dari 75 genera dan 1250 spesies. Dari jumlah tersebut sekitar $80 \%$ terdapat di Asia
Selatan dan Asia Tenggara (Sharma, 1987 dan Uchimura, 1980). Di Indonesia ditemukan sekitar 60 jenis bambu mulai dari dataran rendah sampai pegunungan dengan ketinggian sekitar $300 \mathrm{~m}$ dari permukaan laut (Krisdianto et al., 2000), salah satunya adalah bambu ampel (Bambusa vulgaris Schrad.) yang terdiri dari dua varietas yaitu hijau yang digunakan sebagai pagar dan 
kuning sebagai tanaman hias (Widjaja, 2001).

Saat ini bambu ampel belum memiliki nilai jual dibandingkan dengan jenis bambu lainnya. Bambu ampel jarang digunakan untuk bahan bangunan rumah, furnitur, barang kerajinan tangan, dan produk-produk lain yang memerlukan keawetan cukup lama, karena mudah diserang oleh hama, terutama kumbang bubuk. Kumbang bubuk merupakan organisme perusak kayu yang paling umum dijumpai di Indonesia. Kumbang bubuk mengakibatkan kerusakan yang paling besar pada tanaman bambu. Kumbang bubuk yang paling banyak tersebar di Asia adalah Dinoderus minutus Fabricus, D. brevis Horn dan D. ocellaris Stephen. Namun demikian hanya $D$. minutus yang paling umum dijumpai di Indonesia, dan masyarakat menyebutnya dengan toko atau bubuk (Krisdianto et al., 2000). Kumbang D. minutus berukuran kecil sekitar $3 \mathrm{~mm}$, dan mudah dikenali karena mempunyai kepala tunduk ke bawah, dihiasi dengan sepasang antena yang bersatu dan membesar pada 3 ruas terakhirnya. Tubuhnya hitam atau coklat kehitaman, berbentuk gilig memanjang dengan ujung belakang yang pepat (Gambar 1). Bentuk tubuh yang gilig ini sesuai kegiatannya sebagai penggerek kayu, bambu dan rotan. Kumbang betina meletakkan telur pada liang gerek. Larva yang menetas dari telur akan mengkonsumsi pati yang terdapat dalam jaringan inangnya dengan membuat liang-liang gerek. Aktivitas tersebut membuat kayu atau bambu menjadi rapuh dan hancur (Noerdjito, 1994).

Pati merupakan polisakarida pada bambu yang paling melimpah kedua setelah selulosa. Pati dapat dipisahkan menjadi dua fraksi utama berdasarkan kelarutannya bila dibubur (tritrasi) dengan air panas. Kandungan pati pada bambu ampel cukup tinggi sehingga jenis bambu tersebut banyak mengalami serangan bubuk kayu kering $D$. minutus (Nandika et al., 1994). Bambu ampel harus dihindarkan dari serangan hama kumbang bubuk agar tidak terserang dan menjadi cepat rusak.
Upaya untuk menghindari serangan kumbang bubukperusak bambu yaitu dengan melakukan pengawetan. Menurut Wijayanti (1998), pengawetan bambu ada dua cara yaitu secara tradisional dengan merendam bambu dalam air mengalir, air tergenang atau air asin dan lumpur, dan menggunakan bahan kimia. Pengawetan dengan bahan kimia dinilai kurang ekonomis dan juga tidak ramah lingkungan. Untuk itu dilakukan pengawetan secara tradisional, yaitu dengan cara merendam bambu dalam air mengalir, air tergenang dan di dalam lumpur selama beberapa minggu. Metode perendaman cukup efektif untuk menahan serangan kumbang bubuk, karena dengan perendaman maka zat pati yang terkandung di dalam bambu menjadi berkurang (Nandika et al., 1994). Cara ini merupakan cara tradisional karena tidak menggunakan bahan kimia sehingga tidak memerlukan biaya untuk proses pengawetannya dan juga ramah lingkungan.

Lignin merupakan senyawa kimia yang sangat kompleks, mengandung inti-inti aromatis, termasuk polimer tinggi. Hal ini terbukti dengan mendestilasi lignin, degradasi oleh alkali akan membentuk turunan-turunan benzena. Lignin juga merupakan senyawa yang reaktif, karena mengandung gugus hidroksil, metoksil, dan karbonil dengan berat molekul $\pm 3.000-$ 140.000. Lignin banyak dijumpai pada ruang antara sel dan dinding primer serat kayu. Fungsi utamanya pada tumbuhan adalah sebagai zat perekat yang berhubungan dengan kekuatan dan kekakuan serat kayu sehingga tumbuhan yang besar dapat berdiri kokoh.

Tulisan ini mengemukakan tentang efektivitas perendaman bambu ampel (Bambusa vulgaris Schrad.) dalam tiga media yaitu air tergenang, air mengalir dan lumpur terhadap kandungan pati dengan empat periode waktu perendaman yaitu 7 , 14, 21 dan 28 hari. Diharapkan dengan berkurangnya kadar pati maka bambu tersebut menjadi awet karena makanan utama kumbang bubuk menjadi berkurang. Selanjutnya dilakukan kajian terhadap perubahan sifat fisik dan mekaniknya setelah proses perendaman selesai. 


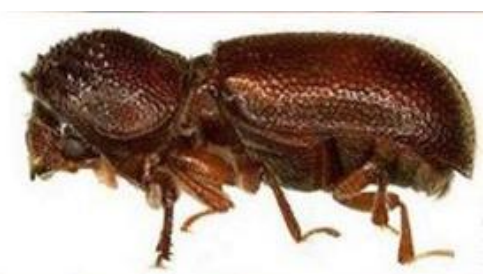

Gambar 1.Kumbang bubuk (Dinoderus minutus)

(Sumber: Setyanto, 2013)

\section{BAHAN DAN METODE}

\section{Bahan dan Alat}

Bahan utama yang digunakan adalah bambu ampel (Bambusa vulgaris Schrad.) yang berasal dari Cikarang, Bekasi, Jawa Barat. Bahan kimia yang digunakan yaitu $\mathrm{H}_{2} \mathrm{O}$, larutan kalium iodida (KI) $20 \%, \mathrm{H}_{2} \mathrm{SO}_{4}$ 1,$25 ; 25 ; 72 \%, \mathrm{H}_{2} \mathrm{SO}_{4} 1 \mathrm{~N}$, larutan natrium tio sulfat $\left(\mathrm{Na}_{2} \mathrm{~S}_{2} \mathrm{O}_{3}\right) 0,1 \mathrm{~N}, \mathrm{HCl} 3$ dan $25 \%$,

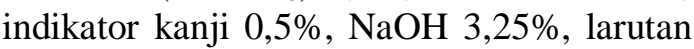
indikator phenolphtalein, dan larutan LurfSchoorl.

Peralatan yang digunakan adalah timbangan analitik, buret, refluks atau pendingin tegak, alat-alat gelas, glinder, oven, eksikator, cawan porselen, pembakar, kaki tiga, kasa asbes, gegep, kertas saring tak berabudan mesin uji mekanik (UTM).

\section{Metode Penelitian}

\section{Persiapan Bahan}

Bambu ampel yang digunakan sebanyak 5 batang dari rumpun yang sama. Lima batang bambu tersebut dipotong sepanjang $35 \mathrm{~cm}$ sebanyak 30 potong untuk masing-masing perlakuan, kemudian potongan bambu tersebut direndam dalam air tergenang,air mengalir dan dalam lumpur selama 7, 14, 21, dan 28 hari. Perendaman dilakukan di Kampung Cimanglid, Desa Sukamantri, Kecamatan Tamansari, Kabupaten Bogor, Jawa Barat.

\section{Prosedur Penelitian}

Bambu yang telah direndam, diangkat, kemudian dibersihkan dengan air sampai bersih, dikeringkan di udara terbuka dan dipotong kecil-kecil dengan panjang \pm 5 $\mathrm{cm}$, kemudian dibersihkan bagian epidermis dan endodermis sehingga yang tersisa hanya bagian dalam saja. Selanjutnya bambu dikeringkan dalam oven pada suhu $40^{\circ} \mathrm{C}$ selama \pm 12 jam. Kemudian bambu yang sudah kering digiling dengan menggunakan mesin glinder sehingga diperoleh bubuk bambu dengan ukuran 20 mesh yang siap untuk dianalisis. Untuk pengujian sifat fisis dan mekanis disediakan dari potongan panjang $35 \mathrm{~cm}$ dengan ukuran contoh uji sesuai Gambar 2.

Analisis kadar pati dilakukan dengan metode titimetri cara Lurf-Schoorl dengan urutan sebagai berikut :

a. Serbuk bambu ditimbang 1-2 g dan dimasukkan ke dalam erlenmeyer asah $250 \mathrm{~mL}$, ditambahkan $25 \mathrm{~mL} \mathrm{HCl} 3 \%$ atau $\mathrm{H}_{2} \mathrm{SO}_{4} 1,25 \%$, dididihkan dengan memakai reflux selama 11/2 hingga 2 jam dan didinginkan. Setelah dingin, larutan dinetralkan dengan $\mathrm{NaOH} \quad 3,25 \%$ (dengan indikator PP), dimasukkan ke dalam labu ukur $250 \mathrm{~mL}$ dan ditepatkan sampai garis tera.

b. Larutan kemudian disaring, dipipet 10 $\mathrm{mL}$ filtrat, dan dimasukkan ke dalam erlenmeyer asah $250 \mathrm{~mL}$. Filtrat selanjutnya ditambahkan $25 \mathrm{~mL}$ larutan Lurf-Schoorl dan $15 \mathrm{~mL}$ aquademin, kemudian dididihkan dengan memakai reflux selama 10 menit dan didinginkan. Setelah dingin, larutan ditambahkan 10 mL larutan KI $20 \%$ dan $25 \mathrm{~mL}$ larutan $\mathrm{H}_{2} \mathrm{SO}_{4} \quad 25 \%$ (hati-hati terbentuk gas $\mathrm{CO}_{2}$ ).

c. Setelah larutan berwarna coklat kemudian ditambahkan larutan kanji $0,5 \%$ (sebagai indikator) dan dititrasi dengan larutan natrium tio sulfat $\left(\mathrm{Na}_{2} \mathrm{~S}_{2} \mathrm{O}_{3}\right)$ 0,1 $\mathrm{N}$ hingga titik akhir tidak berwarna $\left(\mathrm{V}_{1}\right)$. Sebagai blanko dilakukan penetapan dengan $25 \mathrm{~mL}$ air dan $25 \mathrm{~mL}$ 
larutan Lurf-Schoorl $\left(\mathrm{V}_{2}\right)$. Kadar pati dihitung menurut rumus berikut :

Kadar pati $=$ $\frac{\text { fp } \times m g \text { glukosa } \times 0,90}{m g \text { sampel }} \times 100 \% \ldots$ (1)

Keterangan:

$\mathrm{fp}=$ faktor pengenceran

$0,90=$ faktor konversi

Analisis kadar selulosa dan lignin dilakukan dengan metode Chesson, analisis ini diperlukan untuk mendukung pengamatan sifat mekanis bambu setelah direndam dalam air tergenang, air mengalir dan lumpur.

Sampel kering ditimbang 0,5-1g (berat a), ditambahkan $80 \mathrm{ml} \mathrm{H}_{2} \mathrm{SO}_{4} 1 \mathrm{~N}$, kemudian dididihkan di atas penangas air pada suhu $100^{\circ} \mathrm{C}$ selama 1 jam, kemudian didinginkan, disaring, dan residu dicuci sampai netral dengan air panas $\pm 300 \mathrm{~mL}$. Residu yang didapatkan kemudian dikeringkan hingga beratnya konstan pada suhu $105^{\circ} \mathrm{C}$ dan kemudian ditimbang (berat b).

Residu kering ditambahkan $75 \mathrm{~mL}$ $\mathrm{H}_{2} \mathrm{SO}_{4} 72 \%$ dan didiamkan pada suhu kamar selama 4 jam. Kemudian larutan ditambahkan $50 \mathrm{~mL}$ air dan dipanaskan di atas penangas air pada suhu $100^{\circ} \mathrm{C}$ selama 1 jam. Selanjutnya residu disaring dan dicuci dengan aquademin sampai netral $( \pm 400 \mathrm{~mL})$ dan dipanaskan di dalam oven pada suhu $105^{\circ} \mathrm{C}$ sampai beratnya konstan dan ditimbang (berat c). Selanjutnya residu diabukan dan ditimbang (berat d). Perhitungan kadar selulosa dan lignin menurut rumus :

Kadar Selulosa

$=\frac{(b-c)}{a} \times 100 \%$

\section{Kadar lignin}

$=\frac{(c-d)}{a} \times 100 \%$

Keterangan:

$\mathrm{a}=$ Bobot sampel

$\mathrm{b}=$ Bobot penimbangan residu pertama

$\mathrm{c}=$ Bobot penimbangan residu kedua

$\mathrm{d}=$ Bobot abu

Sifat mekanis yang diteliti adalah keteguhan lentur statik (MOE dan MOR) dan keteguhan tarik sejajar serat. Contoh uji diambil dari potongan bambu sepanjang 35 $\mathrm{cm}$ masing-masing 5 ulangan untuk setiap perlakuan. Pembuatan contoh uji mengikuti prosedur Ghavami (1990) dengan bentuk spesimen (Gambar 2).

\section{Pengolahan Data}

1. Data primer dihitung berdasarkan rumus yang relevan dengan masing-masing sifat yang diteliti dan dihimpun dalam bentuk tabel dan grafik.

2. Analisa statistik sebagai alat bantu digunakan untuk melihat sejauh mana perbedaan-perbedaan antar perlakuan yang terjadi sehubungan parameter uji yang dilakukan.

3. Rancangan percobaan yang digunakan adalah Rancangan Acak Lengkap faktorial 3 x 4 yaitu :

Media rendaman : 3 (dalam lumpur, dalam air tergenang dan dalam air mengalir).

Waktu perendaman : $4(7,14,21$ dan 28 hari).

Parameter uji : kadar pati, kerapatan, kadar air, MOE, MOR dan kuat tarik sejajar serat masing-masing 5 ulangan. Sebagai pembanding disediakan contoh uji untuk pengujian tanpa perendaman (kontrol).

\section{HASIL DAN PEMBAHASAN}

\section{A. Kadar Pati}

Hasil analisis kadar pati bambu setelah direndam dalam lumpur, air tergenang dan air mengalir selama 7, 14, 21 dan 28 hari disajikan pada Gambar 3. Kandungan pati pada umumnya meningkat setelah direndam dalam lumpur, air tergenang dan air mengalir. Pada rendaman dalam air mengalir sama sekali tidak terjadi penurunan dibandingkan dengan kontrolnya (tidak direndam). Hal ini disebabkan oleh proses penguraian kandungan pati lebih cepat terjadi oleh kegiatan mikroorganisme air yang mampu mengubah kadar pati bambu yang terdapat di dalam jaringanjaringan pembuluh menjadi suatu senyawa kimia lain yang mudah larut dalam air. Penurunan kadar pati terjadi pada rendaman dalam air tergenang selama 7 dan 21 hari 
masing-masing sebesar $16,7 \%$ dan $14,8 \%$, sedangkan pada rendaman dalam lumpur hanya terjadi selama 28 hari sebesar 13,34\%. Nilai kadar pati ini jauh lebih besar dibandingkan dengan kadar pati bambu ampel hasil penelitian Susilaning dan Suheryanto (2012) yang direndam dalam air mengalir dan air tergenang selama 1-3 bulan.

\section{B. Lignin}

Lignin bersama dengan selulosa merupakan bahan penguat yang terdapat di dalam tumbuhan. Secara kimia, lignin sebenarnya merupakan polimer yang terdiri atas beberapa jenis monomer fenilpropana yang berlainan. Semua lignin mengandung koniferil alkohol, selain itu, lignin yang terdapat dalam sebagian besar tumbuhan dikotil mengandung gugus sinapil (Robinson, 1995). Rata-rata hasil analisis kandungan lignin pada bambu ampel yang sudah direndam dalam lumpur, air tergenang dan air mengalir selama 7, 14, 21 dan 28 hari terlihat pada disajikan dalam Gambar 4.

Kandungan lignin pada semua perlakuan justru mengalami penurunan, berkebalikan dengan dengan kadar pati. Penurunan rata-rata terjadi pada rendaman dalam air tergenang, lumpur dan air mengalir berturut-turut 34,$2 ; 31,7$ dan $28,3 \%$. Penurunan kadar lignin cenderung akan menurunkan kekuatan bambu karena lignin merupakan zat penguat pada tumbuhan.

Kadar lignin selama proses perendaman memang mengalami penurunan jika dibandingkan dengan kontrol. Tetapi bila dibandingkan antara minggu pertama sampai minggu keempat, hasilnya tidak terlalu mengalami perubahan yang signifikan karena lignin tidak begitu larut dalam asam sulfat yang ditambahkan untuk proses hidrolisis. Walaupun lignin tidak begitu larut dalam asam, tetapi dari struktur kimianya akan mengalami perubahan oleh karena penambahan $\mathrm{H}_{2} \mathrm{SO}_{4} 72 \%$ maupun pada saat proses pemanasan (Achmadi, 1990).

\section{Sifat fisis dan mekanis}

Hasil pengujian sifat fisis dan mekanis bambu ampel dengan tiga macam perlakuan perendaman dan 4 periode waktu perendaman dapat dilihat pada Tabel 1. Sifat fisis yang diteliti (kerapatan dan kadar air) setelah perlakuan tidak menunjukan perubahan yang berarti dibandingkan dengan tanpa perlakuan. Modulus elastisitas (MOE) dan keteguhan lentur maksimum (MOR) menurun setelah perlakuan dibandingkan dengan kontrolnya, hal ini disebabkan oleh pengurangan kadar lignin dan penambahan kadar pati setelah perlakuan perendaman 7, 14, 21 dan 28 hari.

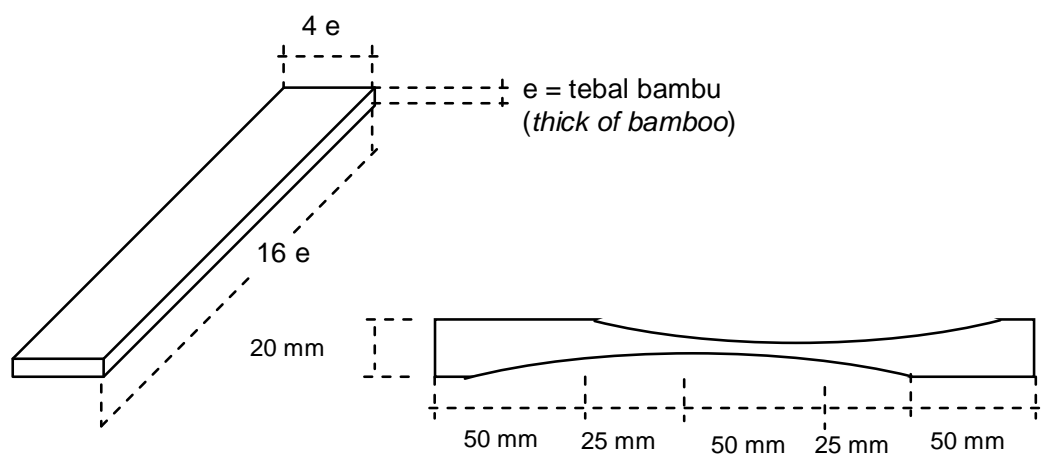

(a)

(b)

Gambar 2. Bentuk dan Ukuran Contoh Uji Sifat Mekanis Bambu. (a) Spesimen Pengujian Lentur Statik. (b) Spesimen Pengujian Tarik // Serat. 


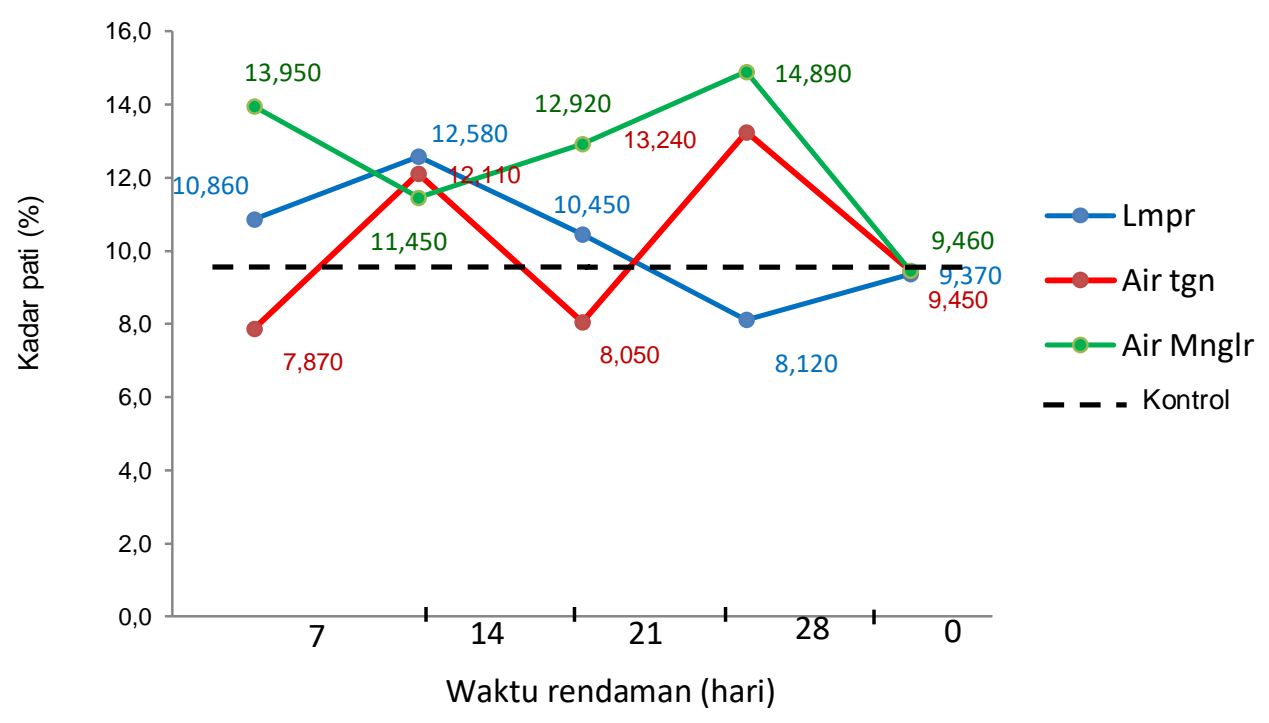

Gambar 3. Nilai Rata-rata Kadar Pati pada 3 Media Rendaman dan 4 Periode Waktu

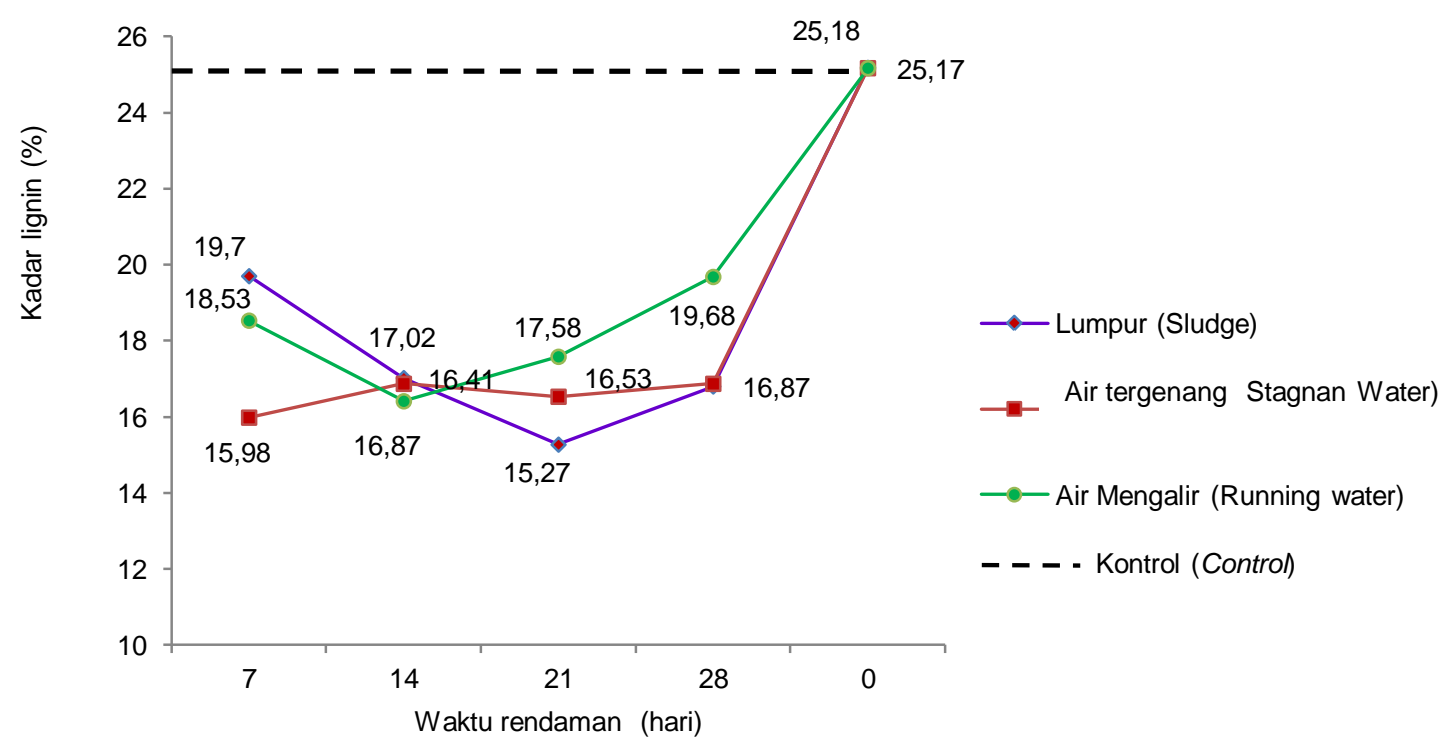

Gambar 4. Nilai Rata-rata Kandungan Lignin pada 3 Media Rendaman dan 4 Periode Waktu 
Tabel 1. Nilai Rata-rata Sifat Fisis dan Mekanis Bambu Ampel pada 3 Media Rendaman

\begin{tabular}{lcccccc}
\hline \multirow{2}{*}{ Media rendaman } & $\begin{array}{c}c \\
\text { Waktu } \\
\text { (hari) }\end{array}$ & \multicolumn{1}{c}{ MOE } & MOR & $\begin{array}{c}\text { Tarik // } \\
\text { serat }\end{array}$ & $\begin{array}{c}\text { Kerapatan } \\
\left(\mathrm{g} / \mathrm{cm}^{3}\right)\end{array}$ & $\begin{array}{c}\text { Kadar Air } \\
(\%)\end{array}$ \\
\cline { 3 - 6 } Lumpur & 7 & $104.596,32$ & $1.016,31$ & $1.227,92$ & 0,736 & 13,66 \\
& 14 & $102.775,93$ & $1.040,39$ & 994,00 & 0,625 & 14,08 \\
& 21 & $88.442,32$ & 734,83 & 575,65 & 0,585 & 14,14 \\
& 28 & $94.194,62$ & 899,56 & $1.051,46$ & 0,636 & 14,08 \\
& 0 & 151466,04 & 1220,39 & 990,43 & 0,64 & 13,52 \\
\hline \multirow{4}{*}{ Air Tergenang } & 7 & $110.249,67$ & $1.225,51$ & $1.340,38$ & 0,776 & 13,35 \\
& 14 & $125.234,16$ & $1.353,67$ & $1.232,02$ & 0,735 & 13,90 \\
& 21 & $122.612,33$ & $1.086,31$ & 994,00 & 0,700 & 13,94 \\
& 28 & $99.004,74$ & 996,31 & $1.569,86$ & 0,725 & 14,09 \\
Air Mengalir & 0 & 151466,04 & 1220,39 & 990,43 & 0,637 & 13,52 \\
\hline & 7 & $95.868,81$ & $1.102,32$ & $1.662,03$ & 0,744 & 13,51 \\
& 14 & $60.216,46$ & 728,84 & $1.027,86$ & 0,566 & 13,36 \\
& 21 & $92.629,50$ & $1.022,63$ & $1.284,94$ & 0,701 & 13,25 \\
& 28 & $120.057,07$ & $1.255,97$ & $1.503,85$ & 0,708 & 13,35 \\
& 0 & $151.466,04$ & $1.220,39$ & 990,43 & 0,637 & 13,52 \\
\hline
\end{tabular}

Tabel 2. Analisis Keragaman Perlakuan Perendaman Bambu Ampel

\begin{tabular}{|c|c|c|c|c|c|c|c|c|}
\hline \multirow{3}{*}{$\begin{array}{l}\text { Sumber } \\
\text { Keragaman }\end{array}$} & \multirow{3}{*}{$\mathrm{db}$} & \multicolumn{7}{|c|}{ Parameter uji } \\
\hline & & \multicolumn{2}{|c|}{$\begin{array}{c}\text { Kerapatan } \\
(\%)\end{array}$} & \multicolumn{2}{|c|}{$\begin{array}{c}\text { Kadar Air } \\
(\%)\end{array}$} & $\begin{array}{c}\mathrm{MOE} \\
\left(\mathrm{kg} / \mathrm{cm}^{2}\right)\end{array}$ & $\begin{array}{c}\mathrm{MOR} \\
\left(\mathrm{kg} / \mathrm{cm}^{2}\right)\end{array}$ & $\begin{array}{c}\text { Kuat Tarik } \\
/ / \text { serat } \\
\left(\mathrm{kg} / \mathrm{cm}^{2}\right)\end{array}$ \\
\hline & & $\mathrm{JK}$ & $\mathrm{F}_{\text {hit }}$ & JK & $\mathrm{F}_{\text {hit }}$ & $\mathrm{F}_{\text {hit }}$ & $\mathrm{F}_{\text {hit }}$ & $\mathrm{F}_{\text {hit }}$ \\
\hline $\begin{array}{l}\text { Media rendaman } \\
\text { (M) }\end{array}$ & 2 & 0,0679 & 4,3373 & 0,3674 & 1,4895 & $\begin{array}{l}5,314 \mathrm{E} \\
+09\end{array}$ & $\begin{array}{l}592612, \\
73\end{array}$ & $\begin{array}{ll}184585 & 3,69 \\
1,1 & 43\end{array}$ \\
\hline $\begin{array}{l}\text { Waktu rendaman } \\
\text { (T) }\end{array}$ & 3 & 0,1037 & $4,4159 *$ & 3,6693 & $9,917 * *$ & $\begin{array}{ll}63278 & \\
0424 & 0,1307\end{array}$ & $\begin{array}{l}212507,0,5481 \\
66\end{array}$ & $\begin{array}{lc}224588 & 2,99 \\
5,3 & 66\end{array}$ \\
\hline $\begin{array}{l}\text { Interaksi } \\
\text { M x T }\end{array}$ & 6 & 0,0705 & 1,5003 & 0,189 & 0,245 & $\begin{array}{l}1,148 \mathrm{E} \\
+10\end{array}$ & $\begin{array}{l}118436 \\
5,3\end{array} 1,5273$ & $\begin{array}{lc}895111 & 0,59 \\
, 82 & 72\end{array}$ \\
\hline Galat & 48 & 0,3759 & & 5,9199 & & $\begin{array}{l}7,744 \mathrm{E} \\
+10\end{array}$ & $\begin{array}{l}620356 \\
4,6\end{array}$ & \\
\hline Jumlah & 60 & 28,7031 & & $\begin{array}{l}11563, \\
295\end{array}$ & & $\begin{array}{l}7,109 \mathrm{E} \\
+11 \\
\end{array}$ & $\begin{array}{l}729083 \\
76\end{array}$ & \\
\hline
\end{tabular}

Keterangan : *) Berbeda nyata

**) Sangat berbeda nyata

JK : Jumlah Kuadrat

$\mathrm{F}_{\text {hit }}$ F hitung 
Waktu perendaman berpengaruh nyata terhadap kerapatan dan sangat nyata terhadap kadar air pada tingkat nyata $5 \%$. Perlakuan perendaman dalam lumpur, air tergenang dan air mengalir pada 4 periode waktu tidak berpengaruh terhadap sifat mekanis yang diteliti. Namun peningkatan atau penurunan kadar pati dan kadar lignin menyebabkan peningkatan atau penurunan sifat mekanis pada setiap media dan waktu perendaman (Tabel 3, 4 dan 5).

Pada rendaman dalam lumpur selama 28 hari, MOE dan MOR menurun dibandingkan dengan kontrolnya, sementara keteguhan tarik sejajar serat pada rendaman 7 hari mencapai nilai lebih tinggi dari kontrolnya. Tetapi pada rendaman 21 hari keteguhan tarik sejajar serat turun drastis sebesar 41,9\%, hal ini disebabkan oleh meningkatnya kadar air dan masuknya zat kimia yang terkandung dalam lumpur sehingga bambu menjadi kaku dan kekuatan lenturnya menjadi lebih rendah. Pada perendaman dalam air tergenang kadar pati menurun pada hari 7 dan ke 21, namun MOE menurun, MOR meningkat pada hari ke-7 dan ke-14. Persentase peningkatan keteguhan tarik sejajar serat mencapai $58,5 \%$ pada rendaman 28 hari. Pada rendaman dalam air mengalir MOE dan MOR mengalami penurunan cukup besar selama periode waktu perendaman, sementara keteguhan tarik sejajar serat mengalami peningkatan cukup besar pula hingga mencapai $67,8 \%$ pada rendaman 7 hari.

Tabel 3. Persentase Peningkatan atau Penurunan Sifat Mekanis pada Perendaman dalam Lumpur

\begin{tabular}{cccccc}
\hline $\begin{array}{c}\text { Waktu peren- } \\
\text { daman (hari) }\end{array}$ & $\begin{array}{c}\text { Kadar pati } \\
(\%)\end{array}$ & $\begin{array}{c}\text { Kadar } \\
\text { lignin } \\
(\%)\end{array}$ & $\begin{array}{c}\text { MOE } \\
\left(\mathrm{kg} / \mathrm{cm}^{2}\right)\end{array}$ & $\begin{array}{c}\text { MOR } \\
\left(\mathrm{kg} / \mathrm{cm}^{2}\right)\end{array}$ & $\begin{array}{c}\text { Keteguhan tarik sejajar } \\
\text { serat }\left(\mathrm{kg} / \mathrm{cm}^{2}\right)\end{array}$ \\
\hline 7 & 14,8 & $-21,8$ & $-30,9$ & $-16,7$ & 24,0 \\
14 & 33,0 & $-32,4$ & $-32,1$ & $-14,7$ & 0,4 \\
21 & 10,5 & $-39,4$ & $-41,6$ & $-37,8$ & $-41,9$ \\
28 & $-14,2$ & $-33,3$ & $-37,8$ & $-26,3$ & 6,2 \\
\hline
\end{tabular}

Keterangan: (-) penurunan

Tabel 4. Persentase Peningkatan atau Penurunan Sifat Mekanis pada Perendaman dalam Air Tergenang

\begin{tabular}{cccccc}
\hline $\begin{array}{c}\text { Waktu peren- } \\
\text { daman (hari) }\end{array}$ & $\begin{array}{c}\text { Kadar pati } \\
(\%)\end{array}$ & $\begin{array}{c}\text { Kadar } \\
\text { lignin } \\
(\%)\end{array}$ & $\begin{array}{c}\mathrm{MOE} \\
\left(\mathrm{kg} / \mathrm{cm}^{2}\right)\end{array}$ & $\begin{array}{c}\text { MOR } \\
\left(\mathrm{kg} / \mathrm{cm}^{2}\right)\end{array}$ & $\begin{array}{c}\text { Keteguhan tarik sejajar } \\
\text { serat }\left(\mathrm{kg} / \mathrm{cm}^{2}\right)\end{array}$ \\
\hline 7 & $-16,7$ & $-36,5$ & $-27,2$ & 0,4 & 35,3 \\
14 & 28,1 & $-33,0$ & $-17,3$ & 10,9 & 24,4 \\
21 & $-14,8$ & $-34,3$ & $-38,8$ & $-10,9$ & 0,4 \\
28 & 40,1 & $-33,0$ & $-20,7$ & $-18,4$ & 58,5 \\
\hline
\end{tabular}

Keterangan: (-) penurunan

Tabel 5. Persentase Peningkatan atau Penurunan Sifat Mekanis pada Perendaman dalam Air Mengalir

\begin{tabular}{cccccc}
\hline $\begin{array}{c}\text { Waktu peren- } \\
\text { daman (hari) }\end{array}$ & $\begin{array}{c}\text { Kadar pati } \\
(\%)\end{array}$ & $\begin{array}{c}\text { Kadar } \\
\text { lignin } \\
(\%)\end{array}$ & $\begin{array}{c}\text { MOE } \\
\left(\mathrm{kg} / \mathrm{cm}^{2}\right)\end{array}$ & $\begin{array}{c}\text { MOR } \\
\left(\mathrm{kg} / \mathrm{cm}^{2}\right)\end{array}$ & $\begin{array}{c}\text { Keteguhan tarik sejajar } \\
\text { serat }\left(\mathrm{kg} / \mathrm{cm}^{2}\right)\end{array}$ \\
\hline 7 & 47,5 & $-26,4$ & $-36,7$ & $-9,7$ & 67,8 \\
14 & 21,0 & $-34,8$ & $-60,2$ & $-40,3$ & 3,8 \\
21 & 36,6 & $-30,2$ & $-38,8$ & $-16,2$ & 29,7 \\
28 & 57,4 & $-21,8$ & $-20,7$ & 2,9 & 51,8 \\
\hline
\end{tabular}

Keterangan: (-) penurunan 


\section{KESIMPULAN}

Kadar pati rata-rata pada Perendaman dalam lumpur meningkat sebesar 27,1\% dibandingkan dengan kontrolnya, kandungan lignin menurun $31,7 \%$. Penurunan terendah MOE sebesar $28,7 \%$ pada rendaman 21 hari dan penurunan terbesar MOR 33,8\% pada rendaman 21 hari. Pada perendaman dalam air tergenang, kadar pati menurun 16,7\% pada 7 hari dan $14,8 \%$ pada rendaman 21 hari. Lignin rata-rata menurun sebesar 34\%, MOE dan MOR menurun pada waktu rendam 28 hari masing-masing sebesar $34,7 \%$ dan $18,4 \%$. Kadar pati rata-rata meningkat sebesar $38,4 \%$ dan lignin menurun $17,2 \%$ pada perendaman dalam air mengalir. Penurunan terbesar MOE dan MOR sebesar 40,3\% pada waktu rendam 14 hari, dan MOR meningkat 2,8\% pada waktu rendam 28 hari.

\section{DAFTAR PUSTAKA}

Achmadi, S.S. 1990. Kimia Kayu. Departemen Pendidikan dan Kebudayaan. Direktorat Jenderal Pendidikan Tinggi Pusat Antar Universitas Ilmu Hayati. Institut Pertanian Bogor. Bogor.

Ghavami, K., 1990. Application of Bamboo as a Low-cost Construction Material. In Rao, I.V.R., Gnanaharan, R. \& Shastry, C.B., Bamboo Current Research, The Kerala Forest Research Institute India, and IDRC Canada: 270-279

Kuswanto. 2000. Laporan Penelitian Bambu. Perendaman Dalam Air dan Lumpur Tiga Jenis Bambu Terhadap Serangan Jamur Pembusuk Putih (Schizophyllum commune). Fakultas Kehutanan Universitas Gadjah Mada. Yogyakarta: 45-63.

Krisdianto, G. Sumarni, dan A. Ismanto. 2000. Himpunan Sari Hasil Penelitian Rotan dan Bambu. Pusat Penelitian Hasil Hutan-Badan Penelitian dan Pengembangan Kehutanan dan Perkebunan. Bogor.
Nandika, D., J. K. Matangaran dan I. G. K. Tapa Darma. 1994. Keawetan dan Pengawetan Bambu.Jurnal Strategi Penelitian Bambu Indonesia. Yayasan Bambu Lingkungan Lestari. Bogor.

Noerdjito, W.A. 1994. Kumbang Dinoderus minutus(Coleoptera: Bostrychidae) : Perilakunya dalam Menggerek Bambu. Himpunan Sari Hasil Penelitian Rotan dan Bambu.Pusat Penelitian Hasil Hutan-Badan Penelitian dan Pengembangan Kehutanan dan Perkebunan. Bogor: 129-135.

Robinson, T. 1995. Kandungan Organik Tumbuhan Tinggi. Penerjemah: Kosasih Padmawinata. Penerbit ITB. Bandung.

Sharma, Y.M.L. 1987. Bamboo in The Asia Pacific Region. Bamboo Research in Asia. Proceeding of Workshop Held in Singapore 28-30 Mei 1980: 99120.

Setyanto, M. 2013. Predator pada Bambu dan Bagaimana Mengatasinya. Bengkel Hijau Indonesia. Bandung.

Susilaning, L dan Suheryanto, D. 2012. Pengaruh Waktu Perendaman Bambu dan PenggunaanBorakBorik Terhadap Tingkat Keawetan Bambu. Prosiding Seminar Nasional Aplikasi Sains \& Teknologi (SNAST) Periode III. Yogyakarta.

Uchimura, E. 1980. Bamboo Cultivation In Lessard, G. \& Chouinard, A., Bamboo Research in Asia, IDRC, Canada: 151-160.

Widjaja, E. A. 2001. Identikit Jenis-jenis Bambu di Kepulauan Sunda Kecil. Puslitbang Biologi. Bogor.

Wijayanti, A. 1998. Pengaruh Perendaman dalam Air dan Lumpur Tiga Jenis Bambu Terhadap Serangan Jamur Pembusuk Putih (Schizophyllum commune). Institut Pertanian Yogyakarta. Yogyakarta. 